\title{
Lymphaticovenular Anastomosis for Persistent Immunosuppressant-Related Eyelid Edema
}

\author{
Isao Koshima, MD ${ }^{1 *}$; Hirofumi Imai, MD; Shuhei Yoshida, MD; Shogo Nagamatsu MD²; Kazunori Yokota, MD² \\ Haruki Mizuta, MD; Mitsunobu Harima, MD; Shuji Yamashita, MD; Laura K. Tom, MD; Ruben Kannan, MD ${ }^{5}$ \\ International Center for Lymphedema, Hiroshima University Hospital, Hiroshima, Japan \\ ${ }^{2}$ Department of Plastic and Reconstructive Surgery, Hiroshima University Hospital, Hiroshima, Japan \\ ${ }^{3}$ Department of Plastic and Reconstructive Surgery, Graduate School of Medicine, University of Tokyo, Tokyo, Japan \\ ${ }^{4}$ Department of Plastic Surgery, Georgetown University School of Medicine, Washington, D.C., USA \\ ${ }^{5}$ Department of Plastic Surgery, Queen Victoria Hospital, East Grinstead, UK
}

\section{Abstract}

Treatment for long-standing edema in the eyelid is challenging. Here, a case of eyelid edema caused by immunosuppressant was treated by lymphaticovenular anastomosis (LVA), a treatment procedure established by Koshima, which required supermicrosurgical techniques. A preauricular lymphatic vessel with a diameter of about $0.2 \mathrm{~mm}$ was anastomosed to a vein $(0.8 \mathrm{~mm})$ using supermicrosurgery. The outcome of this case suggests that LVA is applicable for treatment of persistent eyelid edema related to immunosuppressant therapy.

\section{Introduction}

Eyelid edema is a common postoperative finding that occurs after midface or calvarial craniofacial surgery and soft tissue surgery involving eyelids or removal of head and neck cancers. However, persistent eyelid edema is very rare as almost all cases are temporary with swelling subsiding over time. In contrast, the postoperative lower limb edema can be more persistent after significant trauma or surgery, likely due in part to the position of the region, in a dependent position compared to the upright position of the eyelids. Nonetheless, there are cases of long-standing eyelid edema related to rosacea and cancer treatments, specifically immunosuppressants.

Treatment for long-standing facial and eyelid edema is challenging. Standard physio-compression therapy is difficult due to the form and function of the affected area, which lends the conservative therapy to be ineffective. The face - lips, eyes, and nose - is difficult to create consistent compression even for the most-skilled physiotherapist. Furthermore, the face should be uncovered and kept open for communication and function during daily life activities, unlike the limbs, which can more easily be compressed during regular activities of daily life. Simple resection of eyelid edema is relatively easy, but there is a possibility of recurrence of the edema after surgery. Complete resection of the affected eyelid tissue is difficult because of functional and aesthetic problems.

As an important surgical treatment for lymphedema, the classic lymphaticovenous anastomosis (LVA) was established by Yamada [1] and O'Brien [2-4]. Unfortunately, it was ineffective due to poor technique and the insufficient materials, instruments, and microscopes in 1960-70's. Recent development of LVA with the supermicrosurgical technique was established by Isao Koshima in 1994 [5]. So far, over 2,000 cases of limb edema have been treated by this surgical method, of which many reports conclude with excellent results, providing support for LVA as the firstline treatment for lymphedema [6,7]. We previously reported an effective LVA for persistent facial edema after removal of head and neck cancer [8]. However, the effectiveness of LVA has not yet been established for long-standing eyelid edema with or without previous surgery.

In this report, we present a case with persistent eyelid edema caused by immunosuppressant and treated with successful LVA and lymph node-vein bypass surgery.

\section{Case Report}

A 62-year-old man presented with a complex renal history beginning with severe pyelonephritis at the age of 14 , resulting in renal failure and need for hemodialysis at the age of 21, eventual renal transplantation from his father at the age of 31 , and subsequent continuous immunosuppressant therapy. After decades of immunosuppressant therapy with drugs, he developed bilateral upper and lower eyelid edema. He presented with bloody bullous edema affecting the right side more severely than the left side (Figure 1). The patient suffered from disturbed visual fields bilaterally, which required drainage by a puncture from his ophthalmologist every 3 days. The patient's quality of life and facial function were significantly impacted as he was concerned that the upper eyelid edema was impairing eyelid opening in addition to the overall aesthetic deformity. Despite 6 months of conservative treatment, the right-side eyelids continued to be significantly affected by the edema.

On August 29, 2017, the preoperative indocyanine green (ICG) injection study showed no lymphatic channels or lymph nodes. Under a local anesthesia, LVA was performed in the right preauricular region and a small lymph channel $(0.2 \mathrm{~mm})$ in the subdermal layer and vein $(0.8 \mathrm{~mm})$ was anastomosed with a 50 -micron needle. In addition, a right preauricular lymph node was detected in the same area. The superficial membrane of the node was resected to make a small hole, namely lymphostomy, and the lymphatic fluid was expelled from the lymph node. A transected proximal end of the concomitant vein of the transverse facial artery was anastomosed to the lymphostomy, the hole in the lymph node (Figure 2). There was an excellent flow from both the lymphatic to the vein and the lymph node to the vein.

Immediately after surgery, the right eyelid edema was decreased and continued to progressively improve over 6 weeks on both sides. At 5 months after surgery (Figure 3), there was no recurrence of edema in either set of eyelids. There were no noted serious complications.

\section{Discussion}

\section{Etiology of Chronic Localized Non-Inflamed Eyelid Edema}

Etiology of chronic localized non-inflamed eyelid edema includes trauma or disruptive causes involving surgery, radiation therapy for head and neck cancer [8], periocular hyaluronic acid filler injection for aesthetic treatment [9], and post-vitrectomy silicone leaks [10]. There are also syndromic complexes characterized by chronic eyelid edema. One is a rare form of acne rosacea referred to as Morbihan syndrome [11-14]. Another is Melkersson-Rosenthal syndrome $[15,16]$, which is characterized by a triad of orofacial edema, facial nerve palsy, and furrowing of the tongue. Furthermore, a few immunosuppressants including pemetrexed [17], sirolimus [18], and everolimus [19] also share a link with chronic eyelid edema. Pemetrexed is an antimetabolite agent used for the treatment of mesothelioma and non-small-cell lung cancer. Both sirolimus and everolimus are inhibitors of mammalian target of rapamycin (mTOR) after solid organ transplantation. 


\section{CASE REPORT}
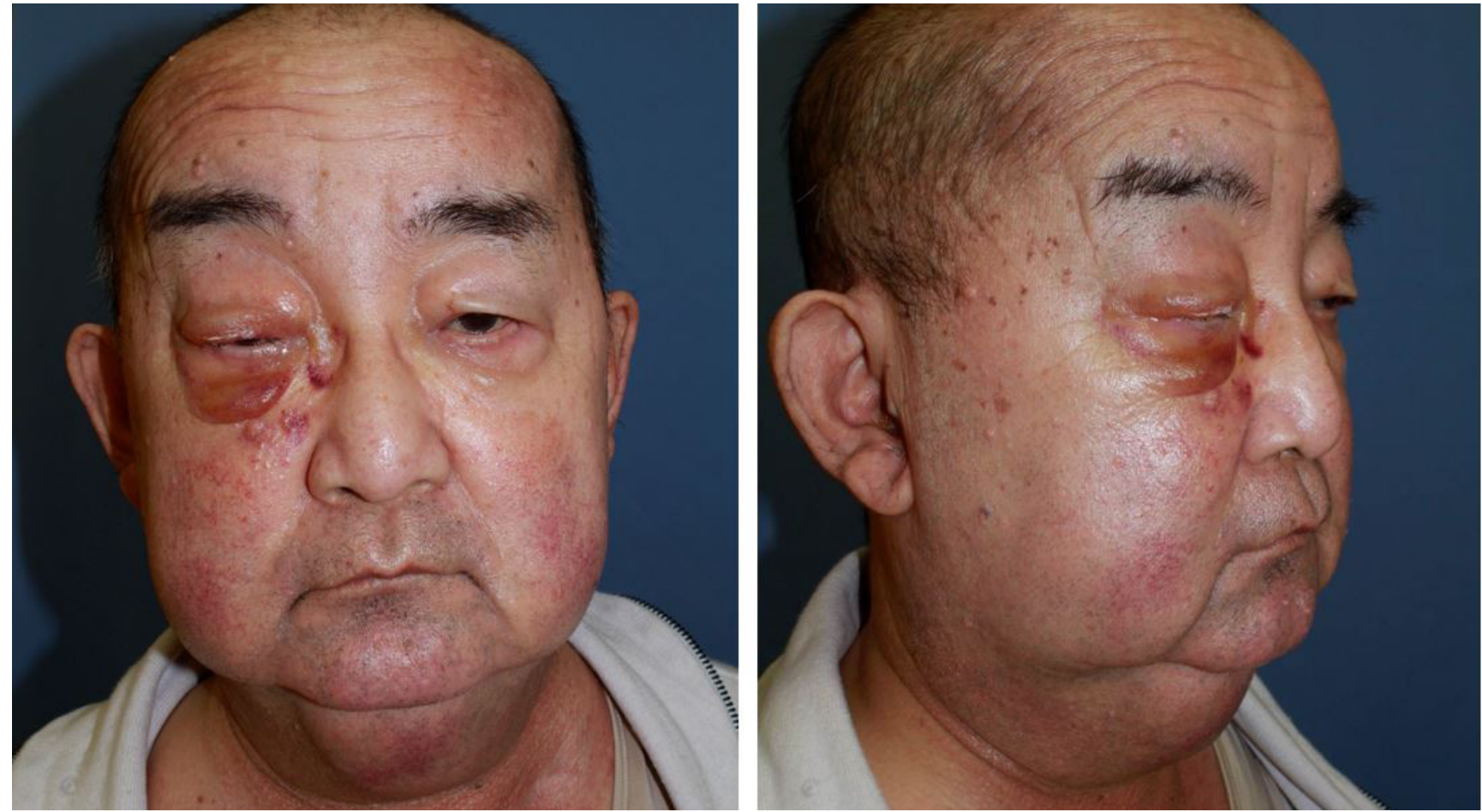

Figure 1. Preoperative appearance.

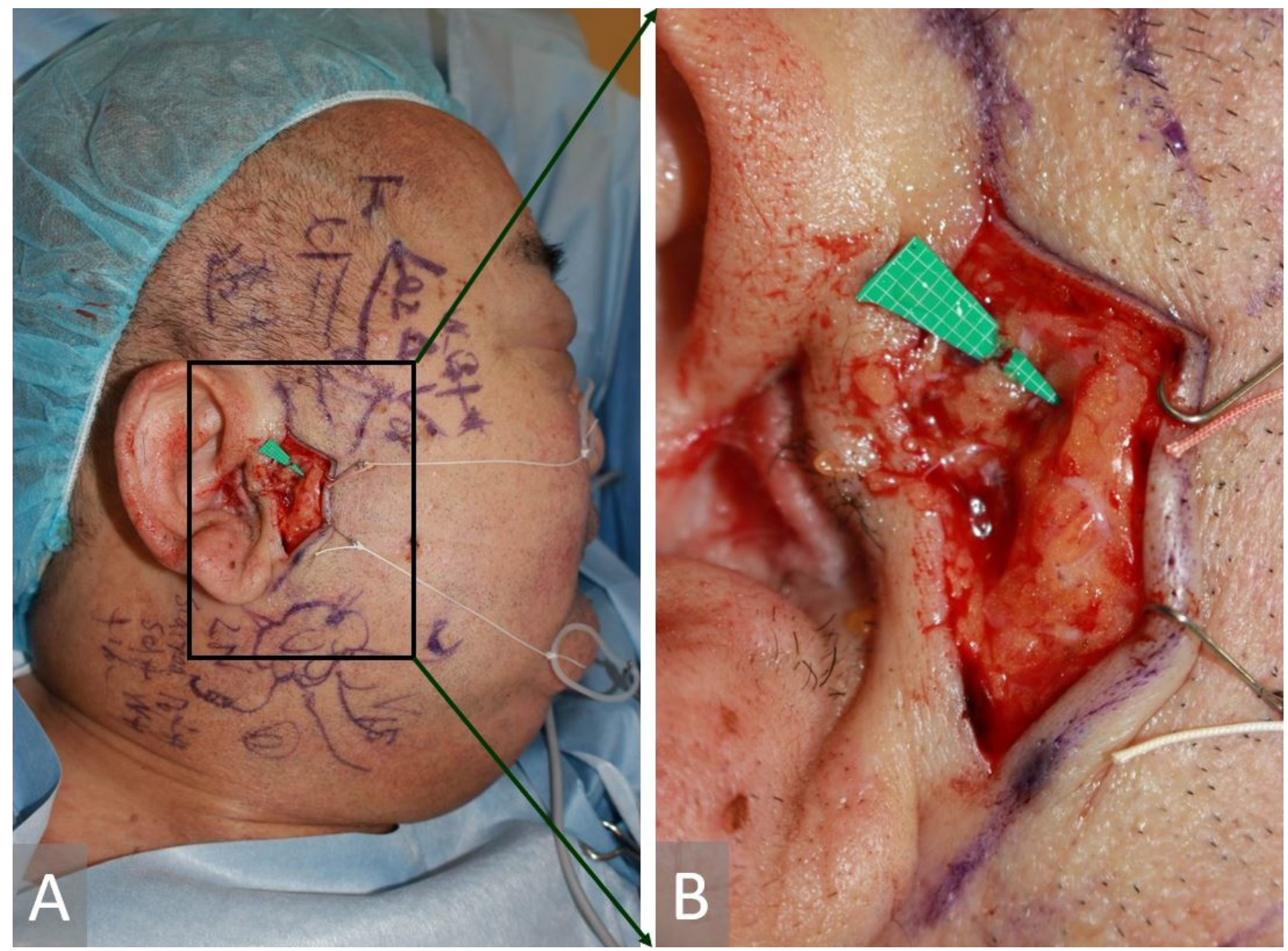

Figure 2. Intraoperative images. (A) The lymphatic channel was anastomosed to the vein, and lymphnodal-venous shunt was established. (B) Close-up view. Square on the green background indicates $1 \mathrm{~mm}$. 

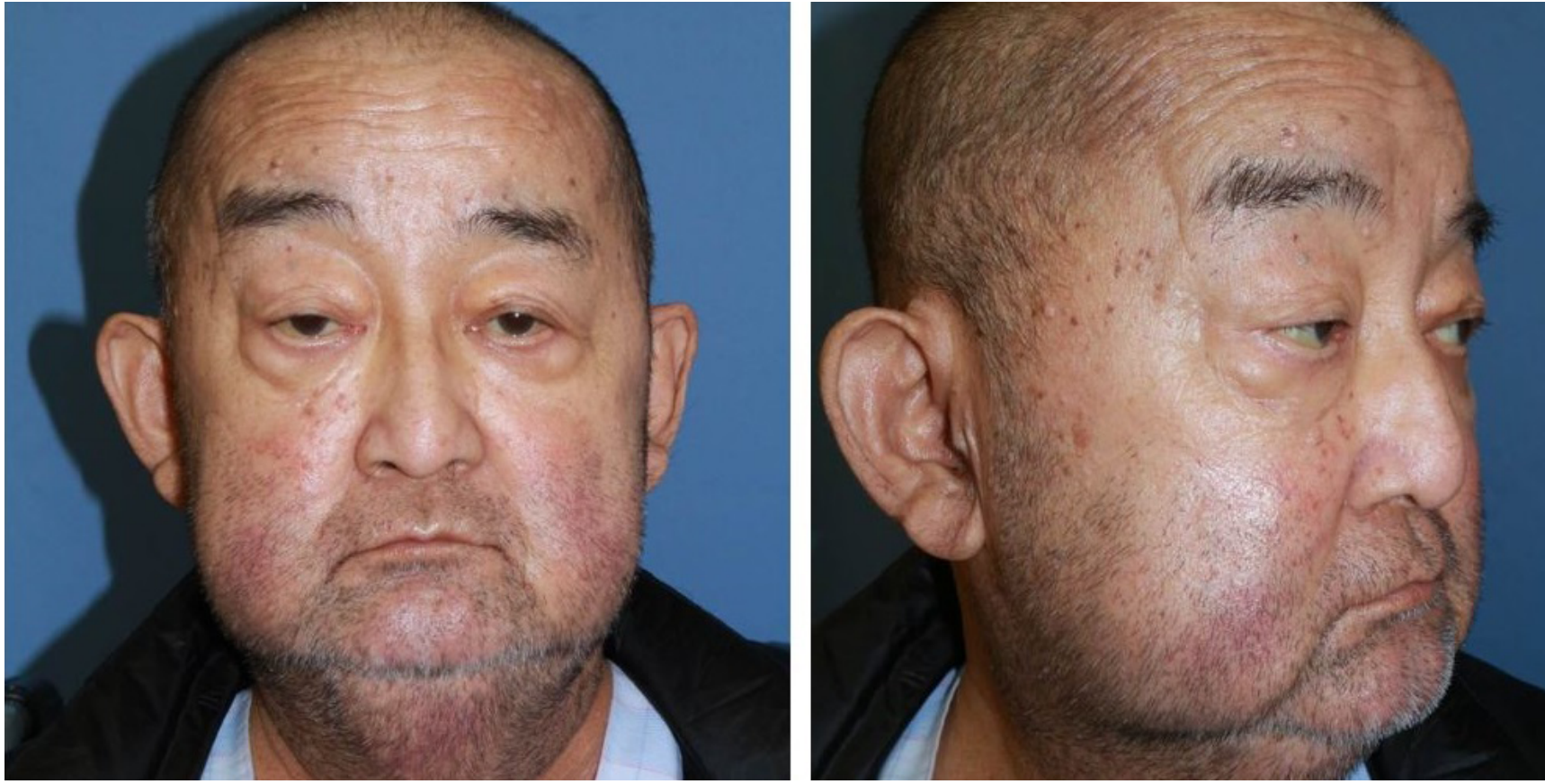

Figure 3. Facial appearance five months after lymphaticovenular anastomosis. Marked improvement of edema is observed.

Immunosuppressant-related lower eyelid edema was reported on persistent eyelid edema following solid organ transplantation. In these cases, the edema persists despite discontinuation of the medication and the surgical excision of the edematous eyelid achieves good results. In this case, it is assumed that the chronic immunosuppressant use is the cause of the chronic eyelid edema by likely injury and dysfunction of the periauricular nodes and/or lymphatic channels around the eyelids. The resulting damage of lymphatics was present, but milder on the left side; however, the persistent nature of the edema on the right necessitated intervention.

\section{Why LVA is Feasible?}

Similar to limb lymphedema, LVA is a curative treatment in which a new drainage pathway is created by constructing a lymphatic-vein bypass $[6,7]$. In this patient, lymph drainage was established by anastomosis of a subdermal venule with a congested lymphatic channel in the preauricular region. In addition, the right preauricular lymph node demonstrated high intra-nodal pressure, which was shunted using a nodal-venous anastomosis to the facial venous system. Both techniques increased the outflow of lymph drainage from the eyelid anatomic region.

Based on this case, anatomic visualization of obstruction was witnessed within the preauricular lymph node, indicating disruption or dysfunction of lymphatic damage proximal to the lymph node. This case also further supports the previous reports of chronic eyelid edema associated with immunosuppressant use.

\section{Sites for Bypassing}

We believed that the possible sites for bypass might be distal (preauricular) and proximal (submental) regions. Based on our previous electron microscopic study, smooth muscle cell degeneration of the lymphatic channel usually occurred from the proximal to the distal site. In addition, under local anesthesia, we needed a less invasive bypass in either site, not on both sides. Therefore, we tried preauricular area for bypassing, rather than submandibular region.

\section{Other Surgical Reconstructions}

Simple resection would not be effective for this patient due to the functional and aesthetic impact. In contrast, a partial resection with the risk of recurrence of the edema exists or even potentially worsening of edema is possible. Another option may include a lymph node or lymphatic channel transfer using groin or axillary tissue as a donor to the preauricular region [20-23]. Submandibular and supraclavicular lymph nodes should be avoided as these donor sites might be affected by the mechanism of damage related to the immunosuppressant. Also, these head and neck donor sites are too invasive to perform under local anesthesia. This is compared to performing an LVA or groin lymphatic transfer, which is easily performed under local anesthesia.

\section{Conclusion}

A case of long-standing eyelid edema related to immunosuppressant is reported here. A novel treatment involving a successful LVA and lymph node-venous bypass surgery under local anesthesia was introduced. These supermicrosurgery techniques are less invasive with lower potential for eyelid malposition compared to eyelid resection. We believe that all persistent eyelid edema could be indicated for LV bypass. It is assumed that the site of bypass is very important in each case. Wide facial and lid edema could be by auricular and submental bypasses. Mild localized lid edema could be an intra-auricular bypass in future.

\section{Article Information}

* Correspondence: Isao Koshima, MD

International Center for Lymphedema, Hiroshima University Hospital, 1-2-3, Kasumi, Minami-ku, Hiroshima City, 734-8551 Japan.

E-mail: koushimaipla@gmail.com

Received: Aug. 13, 2018; Accepted: Oct. 12, 2018; Published: Nov. 13, 2018

DOI: $10.24983 /$ scitemed.imj.2018.00090

Copyright $\odot 2018$ The Author (s). This is an open-access article distributed under the terms of the Creative Commons Attribution 4.0 International License (CC-BY).

\section{Funding: None}

\section{Conflict of Interest: None}

\section{Disclosures}

This paper was presented at the American Society of Reconstructive Mi- 
crosurgery on January 12, 2018 in Arizona, USA, the Chicago Breast \& Lymphedema Symposium on April 26, 2018 in Chicago, USA, the European Federation of Societies for Microsurgery on May 8, 2018 in Belgrade, Serbia, and the Asia Pacific Federation of Societies for Reconstructive Microsurgery on May 12, 2018 in Antalya, Turkey.

\section{Informed Consent}

Informed consent was obtained from the patient for publication of this case report and any accompanying images.

\section{Keywords}

Eyelid edema; lymphaticovenular anastomosis; lymphedema; supermicrosurgery.

\section{References}

1. Yamada Y. The studies on lymphatic venous anastomosis in lymphedema. Nagoya J Med Sci 1969;32(1):1-21.

2. O'Brien BM, Chait LA, Hurwitz PJ. Microlymphatic surgery. Orthoped Clin North Am 1977;8(2):405-424.

3. O'Brien BM, Sykes PJ, Threlfall GN, Browning FS. Micro-lymphaticovenous anastomoses for obstructive lymphedema. Plast Reconstr Surg 1977;60(2):197-211.

4. O'Brien BM, Mellow CG, Khazanchi RK, Dvir E, Kumar V, Pederson WC. Long-term results after microlymphaticovenous anastomoses for the treatment of obstructive lymphedema. Plast Reconstr Surg 1990;85(4):562-572.

5. Koshima I, Kawada S, Moriguchi T, Kajiwara Y. Ultrastructural observation of lymphatic vessels in lymphedema in human extremities. Plast Reconstr Surg 1996;97(2):397-405.

6. Koshima I, Nanba Y, Tsutsui T, Takahashi Y, Itoh S. Long-term follow-up after lymphaticovenular anastomosis for lymphedema in the leg.J Reconstr Microsurg 2003;19(4):209-215.

7. Campisi C, Bellini C, Campisi C, Accogli S, Bonioli E, Boccardo F. Microsurgery for lymphedema: clinical research and long-term results. Microsurgery 2010;30(4):256-260.

8. Mihara M, Uchida G, Hara $\mathrm{H}$, et al. Lymphaticovenous anastomosis for facial lymphoedema after multiple courses of therapy for headand-neck cancer. J Plast Reconstr Aesthetic Surg 2011;64(9):12211225.

9. Yu JTS, Peng L, Ataullah S. Chronic eyelid edema following periocular hyaluronic acid filler treatment. Ophthal Plast Reconstr Surg 2017;33(6):e139-e140.
10. Chalasani R, McNab A. Chronic lymphedema of the eyelid: case series. Orbit 2010;29(4):222-226.

11. Chen DM, Crosby DL. Periorbital edema as an initial presentation of rosacea. J Am Acad Dermatol 1997;37(2 Pt 2):346-348.

12. Bernardini FP, Kersten RC, Khouri LM, Moin M, Kulwin DR, Mutasim DF. Chronic eyelid lymphedema and acne rosacea. Report of two cases. Ophthalmology 2000;107(12):2220-2223.

13. Vasconcelos RC, Eid NT, Eid RT, Moriya FS, Braga BB, Michalany AO. Morbihan syndrome: a case report and literature review. An Bras Dermatol 2016;91(5 suppl 1):157-159.

14. Carruth BP, Meyer DR, Wladis EJ, et al. Extreme eyelid lymphedema associated with rosacea (morbihan disease): case series, literature review, and therapeutic considerations. Ophthalmic Plast Reconstr Surg 2017;33(3S Suppl 1):S34-S38.

15. Reddy DN, Martin JS, Potter HD. Melkersson-Rosenthal syndrome presenting as isolated eyelid edema. Ophthalmology 2017;124(2):256.

16. Belliveau MJ, Kratky V, Farmer J. Melkersson-Rosenthal syndrome presenting with isolated bilateral eyelid swelling: a clinicopathologic correlation. Can J Ophthalmol 2011;46(3):286-287.

17. Mangla N, Carlson A, Wakil A, Wu N, Wladis, EJ. pemetrexed-associated eyelid edema. Ophthal Plast Reconstr Surg 2015;31(6):e155-e157.

18. Logan SA, Thyparampil PJ, Yen MT. Immunosuppressant-related lower eyelid edema in transplant patients. Ophthal Plas. Reconstr Surg 2017;33(3S supp 1) S58-S60.

19. Schear MJ, Rodgers R. A Case of everolimus-induced eyelid edema. Ophthal Plast Reconstr Surg 2018;34(1):e21-e22.

20. Lin CH, Ali R, Chen SC, et al. Vascularized groin lymph node transfer using the wrist as a recipient site for management of postmastectomy upper extremity lymphedema. Plast Reconstr Surg 2009;123(4):1265-1275.

21. Koshima I, Narushima M, Yamamoto Y, Mihara M, lida T. Recent advancement on surgical treatments for lymphedema. Ann Vasc Dis 2012;5(4):409-415.

22. Koshima I, Narushima M, Mihara M, et al. Lymphadiposal flaps and lymphaticovenular anastomoses for severe leg edema: functional reconstruction for lymph drainage system. J Reconstr Microsurg. 2016;32(1):50-55.

23. Yoshida S, Koshima I. [Vascularized lymph channel transfer. In: Surgical Treatments for Lymphedema]. Edited by Koshima I. Tokyo:Person Shobo;2017:235-267. [Article in Japanese]. 